\title{
Women's input into household decisions and their nutritional status in three resource-constrained settings
}

\author{
Michelle J Hindin* \\ The Johns Hopkins Bloomberg School of Public Health, Department of Population and Family Health Sciences, \\ 615 N. Wolfe Street, Baltimore, MD 21205, USA
}

Submitted 5 August 2004: Accepted 10 August 2005

\begin{abstract}
Objective: To understand the role of women's input into household decisions as a possible factor contributing to women's undernutrition in settings where HIV/AIDS and drought have constrained household resources.

Design and setting: Three cross-sectional surveys of non-pregnant women in partnerships without a birth in the last 3 months were analysed. Factors associated with chronic energy deficiency (CED), defined as body mass index of $<18.5 \mathrm{~kg} \mathrm{~m}^{-2}$, were assessed among 1920 women in Zimbabwe, 2870 women in Zambia and 6219 women in Malawi.

Results: Prevalence of CED was $4.2 \%$ in Zimbabwe, $13.5 \%$ in Zambia and $6.7 \%$ in Malawi. In Malawi, women with less input into decisions were more likely to have CED. After multivariable adjustment, each additional decision made by the partner increased the odds of CED in Malawi by 1.08 ( $95 \%$ confidence interval (CI) $1.02-$ 1.15); each additional decision made by the woman decreased the odds of CED by 0.90 (95\% CI 0.88-0.97). Malawian women with all the final say or with partners with no final say had significantly more CED than expected (odds ratio $(\mathrm{OR})=2.88,95 \%$ CI 1.42-5.83 and OR $=1.64,95 \%$ CI 1.06-2.52, respectively), and removing these points increased the magnitude and significance of the linear trends. In Zambia, the relationship was found for urban women only and no associations were found in Zimbabwe.

Conclusions: Input into household decisions may be a key factor in the cycle of drought and CED. Women with both low input and CED may lose productive capacity, putting them at greater risk of food insecurity and potentially HIV/AIDS in high prevalence settings.
\end{abstract}

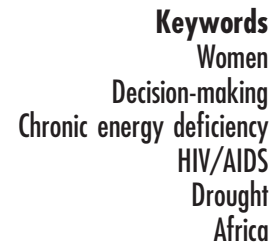

Keywords

cision-making

HIV/AIDS

Africa
It is estimated that over 15 million people are at risk of starvation in Lesotho, Malawi, Mozambique, Swaziland, Zambia and Zimbabwe ${ }^{1}$. This is in part due to a food crisis which has been evolving since the 1992 Southern African drought, and has also been associated with 'alarmingly high prevalence rates' of HIV/AIDS ${ }^{2}$. In the past, households in these nations were able to cope with food crises through the production of food, earning cash from food produced, and relying on trading and bartering. Today HIV/AIDS has led to an erosion of coping mechanisms with regard to food shortages. Over $80 \%$ of the population in this region depends on subsistence agriculture for food, and 7 million agricultural workers have died since $1985^{2}$. In addition, several recent reviews have documented that malnutrition is a major complication of HIV/AIDS and that malnutrition is associated with increased mortality, faster disease progression and decreased functional status ${ }^{3-5}$.

\section{Defining a 'resource-constrained' context}

It is estimated that $52 \%$ of Zimbabweans, $31 \%$ of Malawians and $28 \%$ of Zambians were in need of food aid in $2002-2003^{1}$. By the end of 2001, it was estimated that $33.7 \%$ of adults in Zimbabwe, $21.5 \%$ in Zambia and $15.0 \%$ in Malawi were living with HIV/AIDS ${ }^{2}$. According to a Mission Report to the United Nations in $2003^{6}$, there are several factors in the current food shortage in Southern Africa that make it unique. At national level the food price index has soared, with Zambia, Malawi and Zimbabwe being among the countries most affected ${ }^{7}$. Zimbabwe's political situation has also greatly contributed to the food crisis $^{8}$. International comparisons suggest that these countries perform poorly in terms of human development with Malawi ranking among the lowest of 177 nations (165), followed by Zambia (164) and then Zimbabwe (147). All three countries have experienced a decline in levels of human development from 1995 to the present?

At the household level, this most recent food emergency was worsened by HIV/AIDS through the loss of productive working adults and, in particular, of women, who have been the main providers of household food security ${ }^{6}$. A report from SADC (Southern African Development Community) on 
Malawi, Zambia and Zimbabwe finds that households affected by HIV/AIDS (either through morbidity, mortality or high demographic load characterised by a high dependency ratio or the presence of orphans) have reduced agricultural production and non-farm income, and lower levels of food security ${ }^{1}$. Households have lost breadwinners and caregivers, leaving them even poorer and more vulnerable to starvation, and therefore more vulnerable to HIV/AIDS. In Africa, HIV/ AIDS is associated with malnutrition-related mortality ${ }^{10}$ and reduced food availability ${ }^{11}$. Women have been particularly at risk since they are the primary food providers $^{12}$ and may have to resort to trading sex for food or money, increasing their vulnerability to HIV/ AIDS $^{2}$. Women may also be resource-poor, since they often do not have access to the income from their labour ${ }^{13,14}$.

\section{Decision-making, women's status and food insecurity}

Evidence suggests that women who have lower levels of input into household decisions are more likely to experience undernutrition ${ }^{15}$ or to have lower body mass index $(\mathrm{BMI})^{16,17}$. With drought and HIV/AIDS, women with lower input into household decisions may be at even greatest risk of undernutrition. Household headship may be important as well. Female-headed households have become of increasing concern, due to their growing number attributable to migration and HIV/AIDS, as well as the correlation between female household headship and poverty. On the one hand, women who head households can have more control over household decisions ${ }^{18}$; however, these same households may experience more food insecurity and economic vulnerability ${ }^{19}$. One recent South African study showed that even though femaleheaded households were worse off economically than male-headed households, women in these households reported that they experienced less food insecurity. The authors attribute this result to women's abilities to use social networks ${ }^{20}$. In the three countries under study here, women's level of status is low. Comparison with other countries based on national data shows that Malawi, Zambia and Zimbabwe perform poorly in terms of the gender development index, with Malawi being the worst off (134 out of 144), followed by Zambia (133) and then Zimbabwe (118) .

The present paper explores the relationship between women's input into household decisions and chronic energy deficiency (CED) in three countries that have experienced periodic droughts, high HIV/AIDS prevalence and less favourable gender norms for women. It is expected that women who have more input into household decisions will be less likely to experience CED. In addition, the importance of household headship and whether or not the partner is a usual resident of the household is also explored.

\section{Methods}

\section{Survey methodology and descriptions of the samples}

The 1999 Zimbabwe Demographic and Health Survey, the 2000 Malawi Demographic and Health Survey and the 2001-2002 Zambia Demographic and Health Survey were obtained for the analysis. Each of these surveys collected nationally representative data on reproductive health issues and demographic behaviour from women aged 15-49 years. Technical assistance was provided by Macro International Inc. as part of the MEASURE Demographic and Health Surveys (DHS) project. Macro International Inc. has been conducting DHS surveys since 1986, and funding has been provided primarily by USAID (United States Agency for International Development). The Zimbabwe DHS was collected by Macro and the Central Statistical Office of the Government of Zimbabwe ${ }^{21}$; the Malawi DHS was collected by Macro with the Central Statistical Office in Zomba ${ }^{22}$; and the Zambia DHS was collected by Macro with the Central Statistical Office and the Central Board of Health, Lusaka ${ }^{23}$.

The survey procedures were similar in each country. A list of enumeration areas was prepared from the most recent census in each country. Clusters were selected from enumeration areas and there was a systematic sampling of households from a list of all households that was prepared for each of the selected clusters. All women aged 15-49 years who were either permanent residents of the households in the sample or visitors present in the household on the night before the survey were eligible to be interviewed in the survey. A household survey was undertaken, in which information was collected on each member of the household, including age, sex, education and the person's relationship to the head of the household. This information was used to determine the eligible women in the household. An attempt was made to interview all eligible women. In Zimbabwe, the response rate was $95.2 \%{ }^{21}$; in Malawi the response rate was $97.7 \%{ }^{22}$; and in Zambia the response rate was $96.4 \%{ }^{23}$. Questions about input into household decision-making as well as anthropometric measures were included in these nationally representative surveys.

All non-pregnant, married or cohabiting women who had not given birth in the last 3 months were included in the statistical analyses for this study. All women who reported being in a partnership at the time of the survey were included; however, a variable was created to determine whether or not the partner lived with the respondent or stayed elsewhere, which is a proxy for partner migration. A variable for household headship was also created. Datasets were limited to women respondents who were 'usual residents' of the household. Because there is a different set of nutritional guidelines and weight expectations for pregnant and lactating women, the sample was limited to women who were not currently 
pregnant or had recently given birth. Based on the abovementioned constraints, as well as missing data on the primary outcome or key independent variables, the final sample for analysis included 1920 women in Zimbabwe, 2870 in Zambia and 6219 in Malawi.

\section{Data analysis}

\section{Dependent variable}

Both height and weight data were gathered on all respondents to the DHS surveys. CED, the main outcome variable for this study, is a dichotomous measure based on the standard BMI cut-off of $<18.5 \mathrm{~kg} \mathrm{~m}^{-2}$, which is an internationally recognised standard ${ }^{13}$.

\section{Independent variables}

Sociodemographic and women's characteristics. The sociodemographic characteristics of the sample are divided into two groups: household characteristics and women's characteristics. Urban residence was a dichotomous variable based on the woman's place of usual residence. Household wealth was calculated as a weighted sum of whether or not the household had the following items: electricity, radio, television, scooter, bicycle, cement floor and flush toilet. The weights were calculated as the inverse of the proportion of households in the sample that had these items. Household size was left as a continuous measure of the number of individuals per household. Three additional sociodemographic measures were included to better describe the respondent's partnership. The first was whether or not the woman's partner was living in the same household at the time of the survey; the second measure was whether or not the partner was polygynous; and the third was the reported household head. The number of births the woman had was used as a dichotomous variable coded as whether or not the woman had any births. Women's ages were used as continuous measures. Education was coded in four levels: no schooling, some primary school, completed primary school, and began secondary school or more.

Measures of input into decision-making. Depending on the survey, a different set of domains was included in terms of decision-making. The questions for each survey are shown in Table 1. For each of these questions, the women were given the following response options: (1) themselves (respondent), (2) husband/partner, (3) respondent and husband/partner jointly, (4) someone else, and (5) respondent and someone else jointly. For most questions, the category for someone else was less than $5 \%$ across all countries and all domains. Respondents who reported that someone else had input into the final decisions were omitted, to focus the analysis on decisionmaking within partnerships. A set of dichotomous variables was created for each of the decision-making domains to reflect patterns of decision-making. For each domain, the variable was coded as 1 if the woman had
Table 1 Description of decision-making questions by Demographic and Health Survey

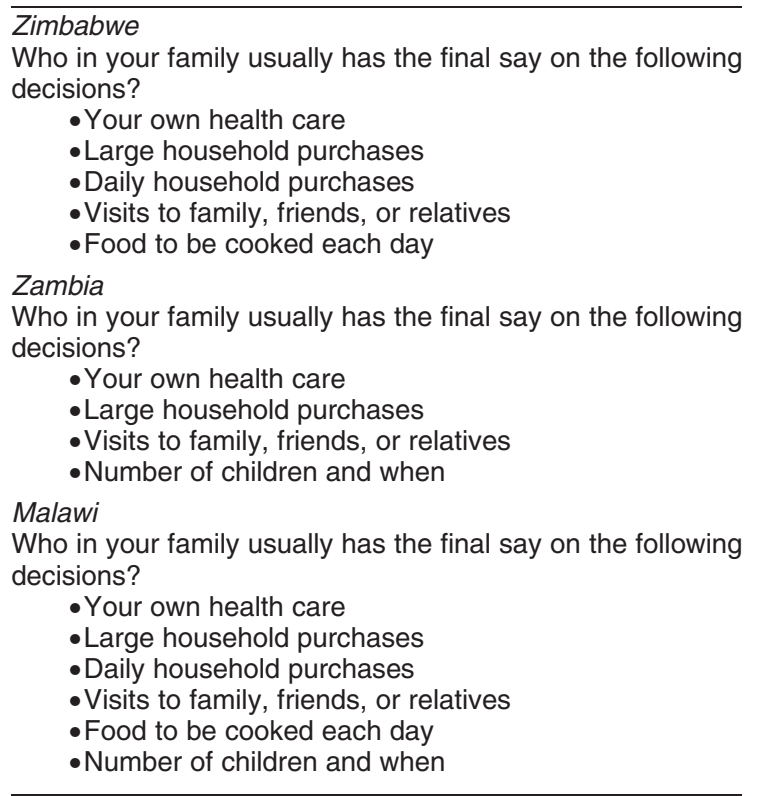

final say over that decision alone and 0 if the woman did not have final say alone. A similar set of dichotomous variables was created for each domain based on whether or not the partner had final say in the decision or whether the final decision was made jointly.

From the sets of dichotomous variables, indices were created to show the number of domains in which women or their partners had the final say or whether final say was made jointly. As the goal of these indices is to represent a range of domains, it was anticipated that alpha coefficients, showing the inter-item correlations, would be moderate - around 0.70. In Zimbabwe, the decisionmaking indices had alpha coefficients as follows: for respondent having the final say (Cronbach's $\alpha=0.58$ ), partner having the final say (Cronbach's $\alpha=0.65$ ) and joint final say (Cronbach's $\alpha=0.67$ ). In Zambia, the corresponding values were as follows: for respondent having the final say (Cronbach's $\alpha=0.50$ ), partner having the final say (Cronbach's $\alpha=0.74$ ) and joint final say (Cronbach's $\alpha=0.73$ ). In Malawi, for respondent having the final say (Cronbach's $\alpha=0.70$ ), partner having the final say (Cronbach's $\alpha=0.76$ ) and joint final say (Cronbach's $\alpha=0.71$ ).

\section{Statistical analyses}

Descriptions of the study populations are provided for each country. Bivariate associations with CED were explored using cross-tabulations. Multivariate logistic regression was used to explore the association between CED and input into household decision-making, with adjustment for confounders including sociodemographic status, urban residence, parity, household size, whether or not the partner co-resided with the woman at the time of 
the survey, household headship, polygyny, age and education. The DHS noted whether husbands were absent or present during the interviews; they were present and listening in $4 \%, 2 \%$ and $5 \%$ of households in Malawi, Zambia and Zimbabwe, respectively. Controlling for husbands' presence did not alter the results of the analyses presented and this variable was omitted from the final models.

\section{Etbical approval}

Since the analyses in this paper were confined to secondary data, primary ethical approval was not required. Approval to analyse the secondary data was obtained from the Johns Hopkins Bloomberg School of Public Health (H.32.03.07.29).

\section{Results}

Table 2 describes the overall distribution of the sociodemographic and women's characteristics. The percentage of women with CED was $4.2 \%$ in Zimbabwe, $13.5 \%$ in Zambia and $6.7 \%$ in Malawi. The patterns of household decision-making are shown in Fig. 1 in terms of the proportion of final decisions made by the respondent, her partner or jointly, according to the respondent's self-report. In Zimbabwe, women reported making substantially more decisions than women in the other two countries. Malawi has the most male-dominated decision-making pattern with men having the final say more than half of the time in decisions about women's own health care, large household purchases and other household purchases.

\section{Multivariable regression of CED}

Table 3 shows the unadjusted associations between CED and the independent variables, and Table 4 shows the logistic regression models of CED, adjusted decisionmaking patterns as well as the other key covariates. Table 3 highlights that the most significant associations are found in Malawi and Zambia, with rural residence, lower household wealth, higher household size and lower education levels being associated with more CED. It is important to note that women who were the heads of household or who had partners living elsewhere were no more or less likely to experience CED.

The models displayed in Table 4 are adjusted for residence, household wealth, having at least one birth, household size, partner lives in household or stays elsewhere, household headship, polygyny, women's age and education. In Zambia and Zimbabwe, older age is associated with less CED, and in Zambia and Malawi, having more household residents and living in an urban area is associated with less CED. In Zambia, more educated women are less likely to have CED. In Malawi, the more domains in which partners had the final say, the higher the risk of CED in women (Table 4, model 1) and for each additional decision made by the partner, the woman's odds
Table 2 Percentage distribution of variables in Zimbabwe, Zambia and Malawi

\begin{tabular}{|c|c|c|c|}
\hline & $\begin{array}{l}\text { Zimbabwe } \\
(n=1920)\end{array}$ & $\begin{array}{c}\text { Zambia } \\
(n=2870)\end{array}$ & $\begin{array}{c}\text { Malawi } \\
(n=6219)\end{array}$ \\
\hline \multicolumn{4}{|c|}{ Chronic energy deficiency } \\
\hline No & 95.8 & 86.5 & 93.3 \\
\hline Yes & 4.2 & 13.5 & 6.7 \\
\hline \multicolumn{4}{|c|}{ Sociodemographic characteristics } \\
\hline \multicolumn{4}{|l|}{ Residence } \\
\hline Rural & 64.6 & 70.6 & 78.9 \\
\hline Urban & 33.4 & 29.4 & 21.1 \\
\hline \multicolumn{4}{|l|}{ Household wealth } \\
\hline Range & $0-128.0$ & $0-174.1$ & $0-130.2$ \\
\hline Mean (SD) & $7.6(11.6)$ & $7.1(14.9)$ & $7.1(13.8)$ \\
\hline \multicolumn{4}{|l|}{ Household size } \\
\hline Range & $1-20$ & $1-26$ & $1-21$ \\
\hline Mean (SD) & $5.2(2.5)$ & $6.3(2.9)$ & $5.3(2.4)$ \\
\hline \multicolumn{4}{|c|}{ Husband/partner lives in household } \\
\hline No & 25.1 & 4.7 & 11.9 \\
\hline Yes & 74.9 & 95.3 & 88.1 \\
\hline \multicolumn{4}{|c|}{ Husband/partner is polygynous } \\
\hline No & 85.8 & 82.5 & 82.7 \\
\hline Yes & 14.2 & 17.5 & 17.3 \\
\hline \multicolumn{4}{|l|}{ Head of household } \\
\hline Husband/partner & 67.6 & 89.8 & 83.6 \\
\hline Woman & 24.2 & 4.4 & 10.7 \\
\hline Other & 8.2 & 5.9 & 5.7 \\
\hline \multicolumn{4}{|c|}{ Woman's characteristics } \\
\hline \multicolumn{4}{|c|}{ Number of births } \\
\hline None & 5.4 & 5.0 & 5.6 \\
\hline One or more & 94.6 & 95.0 & 94.4 \\
\hline \multicolumn{4}{|l|}{ Age (vears) } \\
\hline Range & $15-49$ & $15-49$ & $15-49$ \\
\hline Mean (SD) & $31.7(8.5)$ & $31.1(8.6)$ & $30.8(8.8)$ \\
\hline \multicolumn{4}{|l|}{ Education level } \\
\hline None & 9.4 & 16.2 & 31.9 \\
\hline Some primary & 22.8 & 41.7 & 43.5 \\
\hline Completed primary & 23.0 & 20.7 & 7.7 \\
\hline Secondary or more & 44.7 & 21.4 & 16.9 \\
\hline \multicolumn{4}{|l|}{ Decision-making } \\
\hline \multicolumn{4}{|c|}{ No. of decisions where respondent has final say } \\
\hline Range & $0-5$ & $0-4$ & $0-6$ \\
\hline Mean (SD) & $2.5(1.3)$ & $0.7(0.9)$ & $1.3(1.5)$ \\
\hline \multicolumn{4}{|c|}{ No. of decisions with joint final say } \\
\hline Range & $0-5$ & $0-4$ & $0-6$ \\
\hline Mean (SD) & & $1.1(1.3)$ & $1.4(1.5)$ \\
\hline \multicolumn{4}{|c|}{ No. of decisions where partner has final say } \\
\hline Range & $0-5$ & $0-4$ & $0-6$ \\
\hline Mean (SD) & $1.0(1.3)$ & $2.2(1.5)$ & $3.3(1.9)$ \\
\hline
\end{tabular}

SD - standard deviation.

of having CED were 1.08 times higher (95\% confidence interval (CI) 1.02-1.15). In contrast, women who make more decisions are at lower risk of CED, unless they make all of the decisions, in which case the trend reverses (Table 4, model 4). While the overall association in Zambia is not significant after multivariate adjustment, stratifying by urban/rural residence shows that the associations are substantially larger in the urban areas (data not shown). The odds of an urban woman having CED are 1.19 (95\% CI $1.00-1.41)$ times higher per decision made by the partner compared with rural women, where the odds of having the final say are 0.75 (95\% CI 0.57-0.99).

Figure 2 is designed to further explore the relationship between input into household decisions and CED. The 


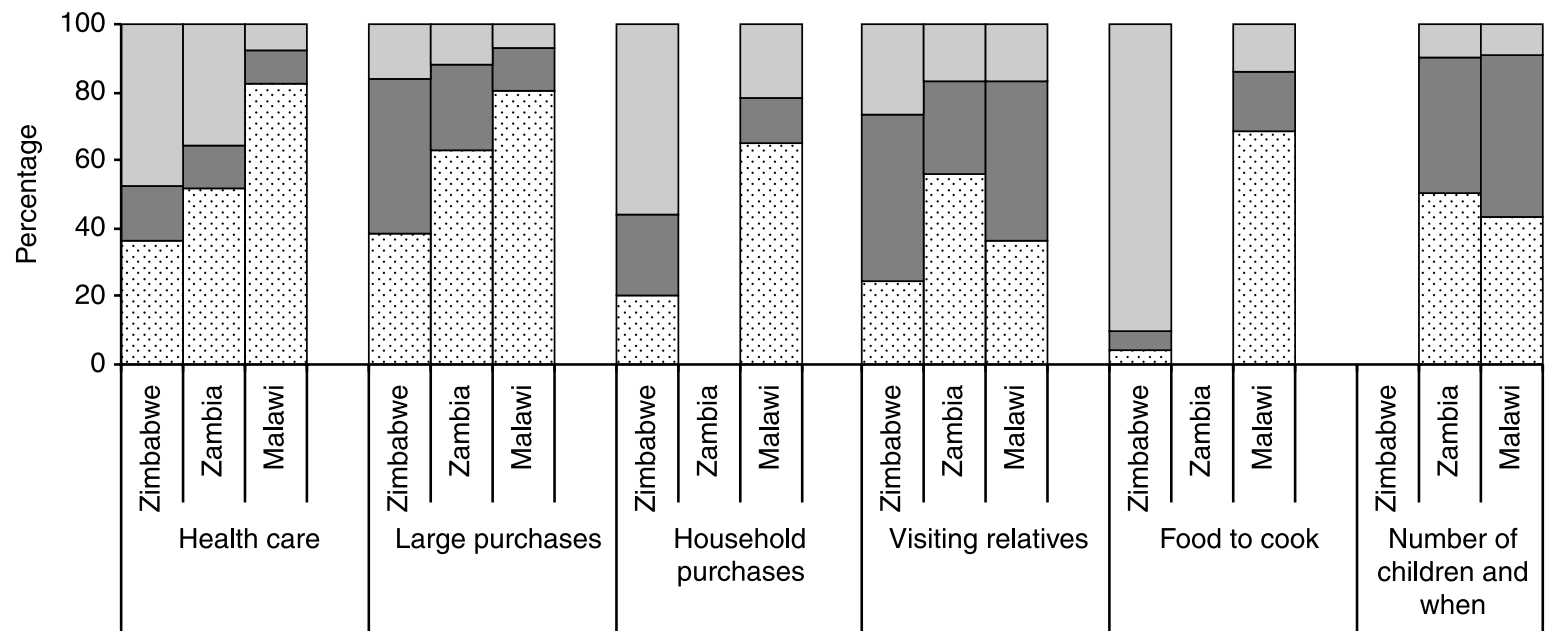

Fig. 1 Percentage distribution of who contributes to the final decision by country and household decision-making domain

figure presents the percentage of women who have CED by their reported decision-making pattern, with the number of final decisions made by the partner, the woman and jointly shown separately (Figs 2a, 2b and 2c, respectively). In addition, the symbols (squares in Malawi, circles in Zambia, and triangles in Zimbabwe) vary in size depending on how many people report making those number of decisions and 95\% CI are used to show the errors around the estimates of CED. The percentages reported in the figures are not adjusted; adjusted results are shown in Table 4.

In Fig. 2a, the percentage of women with CED is shown by reported decision-making by the partner. In both Zambia and Malawi, when partners have the final say in at least one household decision, women are at higher risk of CED (Zambia: odds ratio $(\mathrm{OR})=1.08$, 95\% CI 1.01-1.16 and Malawi: $\mathrm{OR}=1.10,95 \%$ CI $1.04-1.06$ ). After multivariate adjustment, only Malawi remains statistically significant $(P<0.05)$ as shown in model 1 of Table 4 . In Malawi, when partners have the final say in none of the decisions, women are more likely to have CED. When this point is modelled separately from the linear trend in Malawi (Table 4, model 2), the adjusted odds of having CED when the partner makes no decisions is 1.64 times higher (95\% CI 1.06-2.52) than what would be expected if the linear trend continued. The linear trend is stronger without this point, with the adjusted odds ratio of having CED increasing from 1.08 to 1.13 per decision (Table 4 , model 1 vs. model 2).

Figure $2 \mathrm{~b}$ shows the association between the numbers of decisions where the woman has final say and CED. In Malawi, for each additional decision made by the woman, her adjusted odds of CED are 0.90 lower (95\% CI 0.880.97) (Table 4, model 3). As was seen in Fig. 2a, there is an aberrant point in the linear trend where women who make all the household decisions in Malawi appear to be at an increased risk of CED. When this point is removed from the linear trend in Malawi, the linear trend of number of final decisions made by the woman and CED is more significant (OR $=0.85,95 \%$ CI 0.78-0.93) (Table 4, model 4) and when women make all six household decisions without input from their partners, the adjusted odds ratio of having CED is 2.88 times higher than expected for this high level of input (95\% CI 1.42-5.83) (Table 4, model 4). These results suggest that women who have the highest level of input into household decisions could be worse off than expected - comparable to women who have no final say in any of the decisions.

Figure 2c shows the relationship between joint decisionmaking and CED in all three countries. While there is some evidence of a downward trend between joint decisionmaking and CED in Zambia and Malawi, it is not statistically significant.

\section{Discussion}

The three countries studied have experienced not only the devastation of the HIV/AIDS epidemic, but the difficulties associated with chronic droughts and food shortages. The percentage of women with CED was $4.2 \%$ in Zimbabwe, 13.5\% in Zambia and 6.7\% in Malawi. Input into household decisions is most associated with CED in Malawi. It was expected that if women have less input into household decisions, they may also have more limited access to household resources, particularly when many households are constrained as a result of lower agricultural production due to HIV/AIDS and drought. With more limited access to resources, it was anticipated that women would have more CED.

A second scenario seems to be associated with women's increased risk of CED - when either women have all the final say or partners have none of the final say. Under this scenario, male partners contribute little to household decision-making. In societies that have traditionally had 
Table 3 Percentage of women with chronic energy deficiency by sociodemographic characteristics, woman's characteristics and input into decision-making

\begin{tabular}{|c|c|c|c|}
\hline & $\begin{array}{l}\text { Zimbabwe } \\
(n=1920)\end{array}$ & $\begin{array}{c}\text { Zambia } \\
(n=2870)\end{array}$ & $\begin{array}{c}\text { Malawi } \\
(n=6219)\end{array}$ \\
\hline \multicolumn{4}{|c|}{ Sociodemographic characteristics } \\
\hline \multicolumn{4}{|c|}{ Residence } \\
\hline Rural & 4.7 & $15.2^{\star \star \star}$ & $7.2^{\star *}$ \\
\hline Urban & 3.3 & 9.2 & 4.7 \\
\hline \multicolumn{4}{|l|}{ Household wealth } \\
\hline Low & 4.8 & $18.2^{\star \star \star}$ & $7.5^{\star \star \star}$ \\
\hline Medium & 4.9 & 15.2 & 7.4 \\
\hline High & 2.9 & 6.9 & 4.2 \\
\hline \multicolumn{4}{|l|}{ Household size } \\
\hline Smaller & 4.8 & $15.2^{\star *}$ & $7.4^{*}$ \\
\hline Larger & 4.4 & 12.0 & 5.8 \\
\hline \multicolumn{4}{|c|}{ Husband/partner lives in household } \\
\hline No & 4.6 & 16.2 & 7.0 \\
\hline Yes & 4.1 & 13.3 & 6.6 \\
\hline \multicolumn{4}{|c|}{ Husband/partner is polygynous } \\
\hline No & 4.3 & $12.8^{*}$ & 6.4 \\
\hline Yes & 3.7 & 16.5 & 7.6 \\
\hline \multicolumn{4}{|l|}{ Head of household } \\
\hline Husband/partner & 4.1 & 13.4 & 6.4 \\
\hline Woman & 4.3 & 18.4 & 8.4 \\
\hline Other & 5.1 & 10.7 & 7.0 \\
\hline \multicolumn{4}{|c|}{ Woman's characteristics } \\
\hline \multicolumn{4}{|c|}{ Number of births } \\
\hline None & 6.7 & 10.4 & 8.0 \\
\hline One or more & 4.1 & 13.6 & 6.6 \\
\hline \multicolumn{4}{|l|}{ Age } \\
\hline Younger & 5.4 & 6.9 & 13.8 \\
\hline Older & 3.9 & 6.7 & 14.1 \\
\hline \multicolumn{4}{|l|}{ Education level } \\
\hline None & 5.0 & $17.1^{\star \star \star}$ & $7.5^{\star \star}$ \\
\hline Some primary & 3.9 & 14.9 & 6.8 \\
\hline Completed primary & 5.2 & 12.1 & 6.9 \\
\hline Secondary or more & 3.7 & 9.1 & 4.6 \\
\hline \multicolumn{4}{|l|}{ Decision-making } \\
\hline \multicolumn{4}{|c|}{ Final say over health care } \\
\hline Partner & 4.1 & 13.9 & $7.1 \dagger$ \\
\hline Joint & 3.5 & 13.6 & 5.6 \\
\hline Woman & 4.5 & 12.7 & 5.6 \\
\hline \multicolumn{4}{|c|}{ Final say over household purchases } \\
\hline Partner & 4.7 & $\mathrm{~N} / \mathrm{A}$ & $7.1^{*}$ \\
\hline Joint & 4.7 & & 5.6 \\
\hline Woman & 3.9 & & 5.4 \\
\hline \multicolumn{4}{|c|}{ Final say over large purchases } \\
\hline Partner & 4.2 & $14.9^{*}$ & 6.9 \\
\hline Joint & 4.3 & 11.2 & 5.2 \\
\hline Woman & 4.0 & 11.6 & 6.5 \\
\hline \multicolumn{4}{|c|}{ Final say over what to cook } \\
\hline Partner & 0.0 & $\mathrm{~N} / \mathrm{A}$ & $8.1^{\star \star \star}$ \\
\hline Joint & 4.6 & & 6.6 \\
\hline Woman & 4.3 & & 5.5 \\
\hline \multicolumn{4}{|c|}{ Final say over visiting relatives } \\
\hline Partner & 4.3 & 14.4 & 7.3 \\
\hline Joint & 4.2 & 12.3 & 5.6 \\
\hline Woman & 4.2 & 13.3 & 5.4 \\
\hline \multicolumn{4}{|c|}{ Final say over no. of children and when } \\
\hline Partner & N/A & 14.3 & $7.3^{*}$ \\
\hline Joint & & 12.8 & 5.6 \\
\hline Woman & & 11.3 & 5.4 \\
\hline
\end{tabular}

N/A - data not available.

$* \star *, P<0.001$

**, $P<0.01$

*, $P<0.05$.

†, $P<0.10$. male-dominated households, it is unusual to have a male partner who does not make final decisions, even if he is not physically in the household. Women in households with males who do not make decisions may have more CED for a number of reasons. With such high prevalence rates of HIV/AIDS (between 15 and 34\%), one explanation could be that women are doing even more caretaking of sick relatives and having to make up for lost agricultural productivity due to HIV-related morbidity and mortality. In addition, in male-dominated societies, women would be more at risk of CED if male partners do not contribute to household decision-making because men generally play an important emotional and financial role in households. While the observed associations remain unchanged based on household headship or whether or not the partner is in the same household, it is likely that men can still make decisions about their households even if they are not physically present. Decision-making has been found to be related to household headship in the current study (data not shown) as well as in other studies ${ }^{18}$. In-depth interviews of men's roles in the household would be helpful to examine these associations.

Several other studies document that power imbalances in households are associated with poorer health outcomes; in particular, more autonomous women may experience more interpersonal violence ${ }^{24-26}$. These studies point out that the context for women's status and autonomy makes a difference and that when women behave in a manner opposite to traditional gender roles, their well-being may be at greater risk. Further exploration, perhaps with qualitative data, is needed to understand how to ensure that women are empowered without leaving them at greater risk for poor health outcomes.

With regard to Malawi and Zambia, the results generally support the notion that women will be at greatest risk for CED in resource-constrained settings where they have lower status. While women in these three countries have lower status than women in many other countries ${ }^{9}$, it was anticipated that within these countries women who have less input into decisions at the household level would be worse off than their peers. Zimbabwean women have substantially more input into household decisions than do women in Zambia and Malawi. In addition, the women surveyed in Zimbabwe appear to be the least resourceconstrained of the three countries, consistent with international indicators of development? ${ }^{9}$. However, given Zimbabwe's difficulty dealing with droughts and rising economic and political problems leading to healthcare problems ${ }^{8}$, it was surprising to find such a low prevalence of CED. Just $4.2 \%$ of the women surveyed had CED, and in fact a larger proportion of women were obese (9\%) than had CED. The lack of expected association could be due to sample selection issues, with lower participation in the DHS by women with poorer health, or perhaps the fact that women in this survey had the most control over household decisions. 
Table 4 Adjusted odds ratios (OR) and 95\% confidence interval (Cl) of household decision-making patterns with chronic energy deficiency (defined as body mass index $<18.5 \mathrm{~kg} \mathrm{~m}^{-2}$ ) in Zimbabwe, Zambia and Malawi

\begin{tabular}{|c|c|c|c|}
\hline \multirow[b]{2}{*}{ Household decision-making } & \multicolumn{3}{|c|}{ OR $(95 \% \mathrm{Cl})$} \\
\hline & $\begin{array}{l}\text { Zimbabwe } \\
(n=1920)\end{array}$ & $\begin{array}{c}\text { Zambia } \\
(n=2870)\end{array}$ & $\begin{array}{c}\text { Malawi } \\
(n=6219)\end{array}$ \\
\hline \multicolumn{4}{|l|}{ Model 1} \\
\hline Partner has final say (no. of decisions) & $0.97(0.81-1.16)$ & $1.06 \dagger(0.99-1.14)$ & $1.08^{\star \star}(1.02-1.15)$ \\
\hline \multicolumn{4}{|l|}{ Model 2} \\
\hline Partner has final say (no. of decisions) & $0.93(0.70-1.25)$ & $1.08(0.97-1.20)$ & $1.13^{\star \star \star}(1.06-1.21)$ \\
\hline Partner has no final say & $0.89(0.44-1.82)$ & $1.08(0.71-1.64)$ & $1.64^{*}(1.06-2.52)$ \\
\hline \multicolumn{4}{|l|}{ Model 3} \\
\hline Woman has final say (no. of decisions) & $1.01(0.85-1.21)$ & $0.91(0.80-1.03)$ & $0.90^{\star *}(0.88-0.97)$ \\
\hline \multicolumn{4}{|c|}{ Model 4} \\
\hline Woman has final say (no. of decisions) & $1.11(0.90-1.37)$ & $0.90(0.78-1.04)$ & $0.85^{\star \star *}(0.78-0.93)$ \\
\hline Woman has all final say & $0.40(0.12-1.26)$ & $1.05(0.40-2.74)$ & $2.88^{\star \star}(1.42-5.83)$ \\
\hline \multicolumn{4}{|l|}{ Model 5} \\
\hline Joint final say (no. of decisions) & $1.02(0.86-1.20)$ & $0.96(0.89-1.05)$ & $0.96(0.89-1.03)$ \\
\hline
\end{tabular}

Adjusted for urban residence, household wealth, having at least one birth, household size, partner lives in household or stays elsewhere, household headship, polygyny, women's age and education. $\star * \star, P<0.001$.

${ }^{* *}, P<0.01$.

$*, P<0.05$

$\dagger, P<0.10$

Malawi, which had the strongest associations, is the most rural, has the highest fertility rates, the highest illiteracy rate, the lowest gross national income per capita ${ }^{8}$, and the poorest economic and human development indicators of the three countries ${ }^{9}$. While the overall trends for Zambia were similar to those in Malawi, they were significant only among urban women. While Zambia is primarily rural, women who opt to migrate to urban areas may be searching for economic and food security for themselves and their families after failing in the rural areas due to droughts and HIV/AIDS.

There are some important limitations to these results. There is a potential for bias in the samples, although the DHS has attempted to get nationally representative samples. Households that were missed during the census in each country were most likely to be omitted from the sampling frame in the DHS. In addition, since the DHS restricts respondents to those who were either usual residents or those who had spent the previous night in the household, women who are themselves migrant between households may have been overlooked and underrepresented. Data on women's income, access to other sources of income, remittances and social networks, which could all shed light on the issues described in this paper, were not available with DHS data. Finally, while the DHS surveys have very high response rates, there is reason to be concerned that women who had progressed to AIDS declined to be interviewed which would bias the sample towards healthier individuals.

The observed relationship between CED and decisionmaking could be due to a third factor that was unmeasured. In addition, the DHS captures just one measure of women's power to negotiate household resources, and the measures in the DHS vary by setting.
Women's input into decisions was based on self-report, which could be biased. It has been suggested that demographic (and epidemiological) surveys can underestimate the gender bias in food deprivation and nutrition $^{27}$. This study is limited in that no questions were asked about food intake and access, nutritional quality of consumed foods, or cultural or economic preferences about food allocation. These types of questions could be better answered using qualitative methods, such as exploratory ethnographic research and in-depth interviews among focus groups in conjunction with a large national survey like the DHS ${ }^{28}$.

As the data are cross-sectional, the direction of the relationship between women's input into household decisions and CED is unclear. While most would argue that women with limited bargaining power in the household would not be able to negotiate for themselves well enough and thereby develop CED, it is also possible that women who had lower BMI may lose their bargaining power.

While Malawi is historically and presently the most socially conservative of the three countries studied, and the most impoverished. Future research directions include determining whether the observed associations in Malawi may also exist in other settings. More efforts are needed to better quantify decision-making and develop better and more comprehensive measures of women's bargaining position as well as more comprehensive measures of women's energy expenditures and food intake. Qualitative research would also be beneficial. Longitudinal data are needed to investigate the direction of the observed relationships.

Recognising the importance of household decisionmaking patterns for women's health has implications for public health programmes and policies. This study 
a) $\square$ - Malawi $\longrightarrow$ Zambia $\longrightarrow$ Zimbabwe

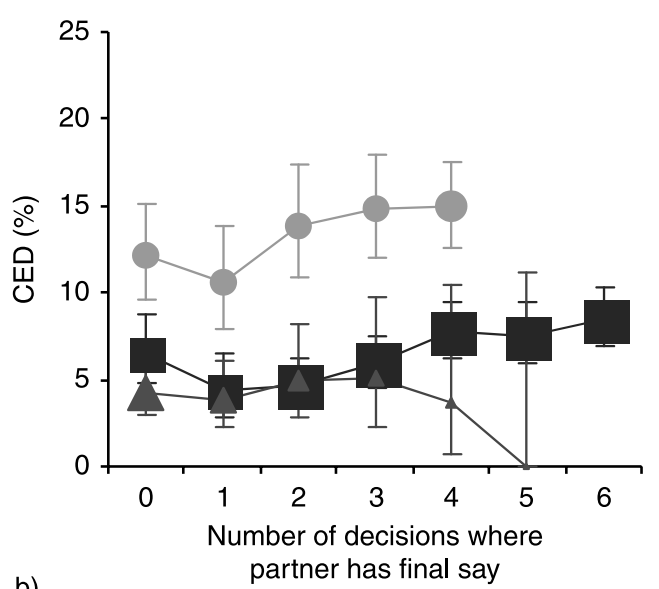

b)
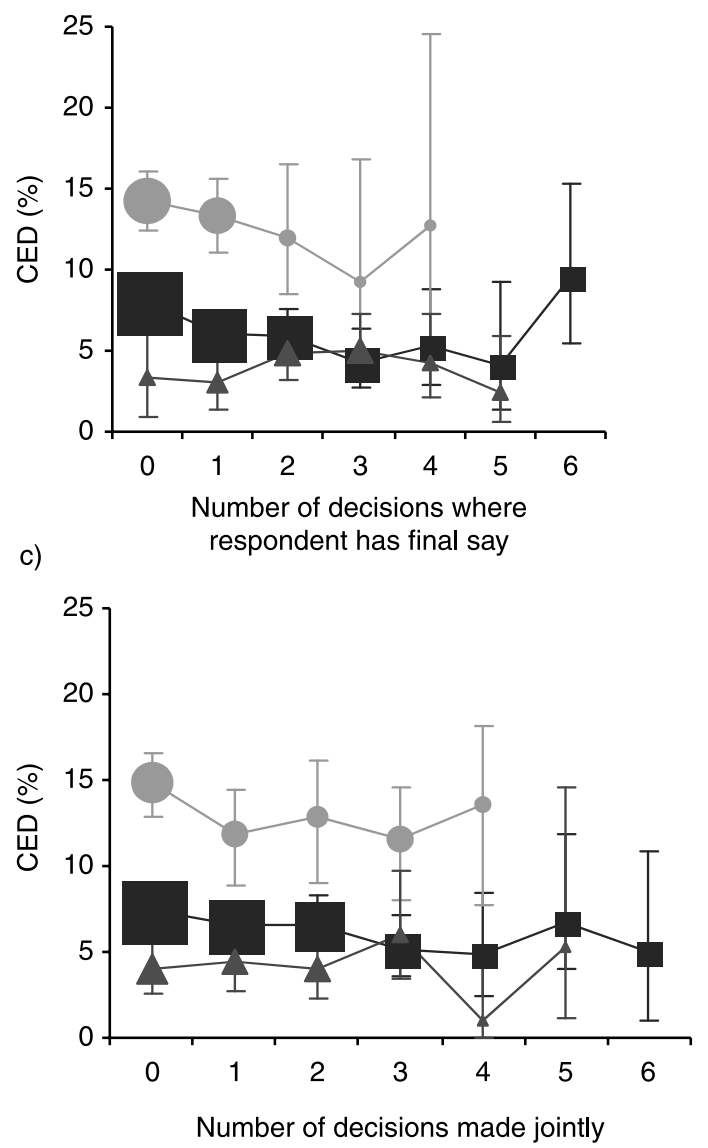

Fig. 2 Percentage of women with chronic energy deficiency (CED) by country and the number of final decisions made by the partner (a), the respondent (b) and jointly (c). Error bars indicate $95 \%$ confidence interval

suggests that successful interventions must consider the gendered balance of power in households in order to prevent further health risks for women. Women's and men's roles and outputs in agricultural production have been of concern, given the importance of agricultural production to household well-being in many developing countries, and both men's and women's roles to enhance household food security should be considered $^{29}$.

Allowing male-dominated decision-making or promoting women's complete independence in decision-making may be harmful for women's health. In addition, the social context for interventions must be clear. Given the periodic droughts in Southern Africa and the role of women as food producers, women are susceptible to using any means necessary to provide food security, even trading sex for food, putting themselves at further risk of HIV/AIDS. Interventions to combat the impact of HIV/AIDS and drought in these households, which are among the most resource-challenged worldwide, must consider women's roles, particularly in agricultural production, and help women to provide adequate food intake for themselves and their families.

\section{References}

1 Southern African Development Community (SADC) Food, Agriculture and Natural Resources (FANR) Vulnerability Assessment Committee (VAC). Towards Identifying Impacts of HIV/AIDS on Food Security in Southern Africa and Implications for Response: Findings from Malawi, Zambia and Zimbabwe. Harare, Zimbabwe: SADC FANR VAC, 2003.

2 The Joint United Nations Programme on HIV/AIDS (UNAIDS). UNAIDS Fact Sheet: HIV/AIDS and Food Security, September 2003 [online]. Available at http:// www.unaids.org $/ \mathrm{html} / \mathrm{pub} / \mathrm{publications} /$ fact-sheets $03 / \mathrm{fs}$ food_security_2003_en_doc.htm

3 Grinspoon S, Mulligan K. Weight loss and wasting in patients infected with human immunodeficiency virus. Clinical Infectious Diseases 2003; 36(Suppl. 2): S69-78.

4 Salomon J, De TP, Melchior JC. Nutrition and HIV infection. British Journal of Nutrition 2002; 87(Suppl. 1): S111-9.

5 Wanke CA, Silva M, Ganda A, Fauntleroy J, Spiegelman D, Knox TA, et al. Role of acquired immune deficiency syndrome-defining conditions in human immunodeficiency virus-associated wasting. Clinical Infectious Diseases 2003; 37(Suppl. 2): S81-4.

6 Morris JT, Lewis S. Mission Report: Lesotho, Malawi, Zambia, and Zimbabwe 22-29 January 2003. New York: United Nations, 10 February 2003.

7 Rukuni M. Africa: addressing growing threats to food security. Journal of Nutrition 2002; 132(11): 3443S-8S.

8 Focusing on health in the crisis in Zimbabwe. Lancet 2002; 359(9305): 455.

9 United Nations Development Programme (UNDP). Human Development Report 2004: Cultural Liberty in Today's Diverse World. New York: UNDP, 2005.

10 Zachariah R, Spielmann MP, Harries AD, Salaniponi FM. Moderate to severe malnutrition in patients with tuberculosis is a risk factor associated with early death. Transactions of the Royal Society of Tropical Medicine and Hygiene 2002; 96(3): 291-4.

11 Niyongabo T, Henzel D, Ndayishimyie JM, Melchior JC, Ndayiragije A, Ndihokubwayo JB, et al. Nutritional status of adult inpatients in Bujumbura, Burundi (impact of HIV infection). European Journal of Clinical Nutrition 1999; 53(7): 579-82.

12 Gittinger JP. Household Food Security and The Role of Women. Report No. 96. New York: World Bank, 1990

13 James WP, Ferro-Luzzi A, Waterlow JC. Definition of chronic energy deficiency in adults. Report of a working party of the 
International Dietary Energy Consultative Group. European Journal of Clinical Nutrition 1988; 42(12): 969-81.

14 Abbas JD. Gender asymmetries in intrahousehold resource allocation in Sub-Saharan Africa: some policy implications for land and labor productivity. In: Haddad L, Hoddinott J, Alderman $\mathrm{H}$, eds. Intrabousehold Resource Allocation in Developing Countries: Models, Methods and Policy. Baltimore, MD: The Johns Hopkins University Press, 1997; 249-62.

15 Hindin MJ. Women's power and anthropometric status in Zimbabwe. Social Science \& Medicine 2000; 51(10): 1517-28.

16 Bindon JR, Vitzthum VJ. Household economic strategies and nutritional anthropometry of women in American Samoa and highland Bolivia. Social Science \& Medicine 2002; 54(8): 1299-308

17 Baqui AH, Arifeen SE, Amin S, Black RE. Levels and correlates of maternal nutritional status in urban Bangladesh. European Journal of Clinical Nutrition 1994; 48(5): 349-57.

18 Posel DR. Intra-family transfers and income-pooling: a study of remittances in Kwazulu-Natal. South African Journal of Economics 2001; 69(3): 501-28.

19 Rose D, Charlton KE. Quantitative indicators from a food expenditure survey can be used to target the food insecure in South Africa. Journal of Nutrition 2002; 132(11): 3235-42.

20 Lemke S, Vorster HH, van Rensburg NS, Ziche J. Empowered women, social networks and the contribution of qualitative research: broadening our understanding of underlying causes for food and nutrition insecurity. Public Health Nutrition 2003; 6(8): 759-64.

21 Central Statistical Office, Zimbabwe/Macro International Inc.
Zimbabwe Demographic and Health Survey 2000. Calverton, MD: National Statistics Office, Central Board of Health/ORC Macro, 2001.

22 National Statistical Office, Malawi/ORC Macro. Malawi Demographic and Health Survey 2000. Zomba, Malawi/Calverton, MD: National Statistics Office/ORC Macro, 2001.

23 Central Statistical Office, Zambia/Central Board of Health, Zambia/ORC Macro. Zambia Demographic and Health Survey 2001-2002. Calverton, MD: Central Statistical Office/Central Board of Health/ORC Macro, 2004.

24 Hindin MJ, Adair LS. Who's at risk? Factors associated with intimate partner violence in the Philippines. Social Science $\mathcal{E}$ Medicine 2002; 55(8): 1385-99.

25 Jewkes R. Intimate partner violence: causes and prevention. Lancet 2002; 359(9315): 1423-9.

26 Koenig MA, Ahmed S, Hossain MB, Khorshed Alam Mozumder AB. Women's status and domestic violence in rural Bangladesh: individual- and community-level effects. Demography 2003; 40(2): 269-88.

27 Messer E. Intra-household allocation of food and health care: current findings and understandings - introduction. Social Science \& Medicine 1997; 44(11): 1675-84.

28 Scrimshaw SCM. Combining quantitative and qualitative methods in the study of intra-household resource allocation. In: Rogers BL, Schlossman NP, eds. Intra-bousebold Resource Allocation: Issues and Methods for Development Policy and Planning. Tokyo: United Nations University Press, 1990; 86-98.

29 Laier JK, Davies S, Milward K, Kennan J. Gender, Housebold Food Security and Coping Stratagies. Report No. 14. Brighton: Institute of Development Studies, 1996. 